\title{
A NONLINEAR VERSION OF HALANAY INEQUALITY AND APPLICATION TO NEURAL NETWORKS THEORY
}

\author{
NASSER-EDDINE TATAR
}

Abstract. We establish an exponential stability result for a delayed Hopfield neural network. This is proved in case one or more of the activation functions fails to satisfy the standard Lipschitz continuity condition. We use a nonlinear version of Halanay inequality, which we prove here.

Mathematics subject classification (2010): 92B20, 93D20, 34D20, 37C75.

Keywords and phrases: Hopfield neural network, exponential stabilization, non-Lipschitz continuous activation functions, nonlinear Halanay inequality.

\section{REFERENCES}

[1] K. Aminian, B. Thomas, H. I. Bilgesu, S. Ameri And A. Oyerokun, Permeability distribution prediction, SPE Paper, Proceeding of SPE Eastern Regional Conference, October 2001.

[2] G. BAO AND Z. ZENG, Analysis and design of associative memories based on recurrent neural network with discontinuous activation functions, Neurocomputing 77 (2012), 101-107.

[3] A. BhATT AND H. B. Helle, Committee neural networks for porosity and permeability prediction from well logs, Geophys. Prospect. 50, (2002), 645-660.

[4] Z. CAI AND L. HUANG, Existence and global asymptotic stability of periodic solution for discrete and distributed time-varying delayed neural networks with discontinuous activations, Neurocomputing 74 (2011), 3170-3179.

[5] J. CAO AND D. W. C. Ho, A general framework for global asymptotic stability analysis of delayed neural networks based on LMI approach, Chaos, Solitons and Fractals 24 (2005), 1317-1329.

[6] J. A. CID, On uniqueness criteria for systems of ordinary differential equations, J. Math. Anal. Appl. 281 (2003), 264-275.

[7] A. Constantin, On Nagumo's theorem, Proc. Japan Acad. 86, Ser. A. (2010), 41-45.

[8] P. Delellis, M. Di Bernardo, And G. Russo, On QUAD, Lipschitz, and Contracting Vector Fields for Consensus and Synchronization of Networks, IEEE Trans. Circuits and Syst. - I: 58 (3) (2011), 576-583.

[9] M. Forti, M. Grazzini, P. Nistri And L. PAnCioni, Generalized Lyapunov approach for convergence of neural networks with discontinuous or non-Lipschitz activations, Physica D 214 (2006), 88-99.

[10] R. Gavaldi And H. T. Siegelmann, Discontinuous in recurrent neural networks, Neural Comput. 11 (1999), 715-745.

[11] E. Hille, Lectures on Ordinary Differential Equations, Addison-Wesley, Reading, Mass. 1969.

[12] J. T. HoAG, Existence and uniqueness of a local solution for $x^{\prime}=f(t, x)$ using inverse functions, Electron. J. Diff. Eqs. 2013, No, 124, 1-3.

[13] Y. HUANG, H. ZHANG AND Z. WANG, Dynamical stability analysis of multiple equilibrium points in time-varying delayed recurrent neural networks with discontinuous activation functions, Neurocomputing 91 (2012), 21-28.

[14] Y. JiAng, B. YAng, J. Wang And C. Shao, Delay-dependent stability criterion for delayed Hopfield neural networks, Chaos, Solitons and Fractals 39 (2009), 2133-2137.

[15] L. JONG-SE AND K. JungWhan, Reservoir porosity and permeability estimation from well logs using fuzzy logic and neural networks, SPE Asia Pacific Oil and Gas Conference and Exhibition. Perth, Australia 2004. 
[16] B. Kosko, Neural Network and Fuzzy System - A Dynamical System Approach to Machine Intelligence, New Delhi: Prentice-Hall of India 1991.

[17] J.-S. Lim, Reservoir properties determination using fuzzy logic and neural networks from well data in offshore Korea, J. Pet. Sci. Engi., 49 (3-4), (2005), 182-192.

[18] J. LiU, X. LiU AND W.-C. XIE, Global convergence of neural networks with mixed time-varying delays and discontinuous neuron activations, Information Sciences 183 (2012), 92-105.

[19] H. LU, F. L. ChUnG AND Z. HE, Some sufficient conditions for global exponential stability of delayed Hopfield neural networks, Neural Netw. 17 (2004), 537-544.

[20] S. Mohaghegh, R. Arefi, S. Ameri And D. Rose, Design and development of an artificial neural network for estimation of permeability, Society of Petroleum Engineers. SPE 28237, 1994.

[21] L. A. Nagasaki Costa, C. Maschio AND D. J. Schiozer, Application of artificial neural networks in a history matching process, J. Petr. Sci. Eng., 2014.

[22] Q. M. SADEQ AND W. I. B. YUSOFF, Porosity and permeability analysis from well logs and core in fracture, vugy and intercrystalline carbonate reservoirs, J. Aquac. Res. Development. 2015, 6:10 DOI:10.4172/2155-9546.1000371.

[23] T. P. Sampaio, V. J. M. Ferreira Filho, A. Sa Neto, An application of feed forward neural network as nonlinear proxies for use during the history matching phase, Latin American and Caribbean Petroleum Engineering Conference, SPE122148. Cartagena, Colombia, 31 May-3 June, 2009.

[24] T. SHEN, Y. ZhANG, Improved global robust stability criteria for delayed neural networks, IEEE Trans. Circuits Syst. II54 (8) (2007), 715-719.

[25] V. SINGH, Simplified LMI condition for global asymptotic stability of delayed neural networks, Chaos, Solitons \& Fractals 29 (2006), 470-473.

[26] Q. Song, Novel criteria for global exponential periodicity and stability of recurrent neural networks with time-varying delays, Chaos, Solitons and Fractals 36 (2008), 720-728.

[27] P. TAhmaSEBi AND A. HeZARKhani, A fast and independent architecture of artificial neural network for permeability prediction, J. Pet. Sci. Eng., Vol. 86-87 (2012), 118-126.

[28] N.-E. TATAR, Hopfield neural networks with unbounded monotone activation functions, Adv. Artificial Neural Netw. Syst. 2012 (2012), ID571358, 1-5.

[29] N.-E. TATAR, Control of systems with Hölder continuous functions in the distributed delays, Carpathian J. Math. 30 (1) (2014), 123-128.

[30] N.-E. TATAR, Long time behavior for a system of differential equations with non-Lipschitzian nonlinearities, Adv. Artificial Neural Network. Syst. Vol. 2014, Article ID 252674, (2014), 7 pages. doi:10.1155/2014/252674.

[31] N.-E. TATAR, Haraux type activation functions in neural network theory, British J. Math. Math. Computer Sci. 4 (22), (2014), 3163-3170.

[32] N.-E. TATAR, Neural networks with delayed Hölder continuous activation functions, Int. J. Artificial Intelligence Mechatronics 2 (6) (2014), 156-160.

[33] N.-E. TATAR, Hölder continuous activation functions, Adv. Diff. Eqs. Control Processes in Neural Networks, 15 (2) (2015), 93-106.

[34] N.-E. TATAR, Exponential decay for a system of equations with distributed delays, J. Appl. Math., Vol. 2015, (2015), Article ID 981383, 6 pages.

[35] N.-E. TATAR, On a general nonlinear problem with distributed delays, J. Contemporary Math. Anal., 52 (4), (2017), 184-190.

[36] J. WANG, L. HUANG AND Z. GUO, Global asymptotic stability of neural networks with discontinuous activations, Neural Networks 22 (2009), 931-937.

[37] H. WU, Global exponential stability of Hopfield neural networks with delays and inverse Lipschitz neuron activations, Nonlinear Anal., Real World Appl. 10 (2009), 2297-2306.

[38] H. Wu, F. TAO, L. QIN, R. SHI AND L. HE, Robust exponential stability for interval neural networks with delays and non-Lipschitz activation functions, Nonlinear Dyn. 66 (2011), 479-487.

[39] H. WU AND X. XUE, Stability analysis for neural networks with inverse Lipschizian neuron activations and impulses, Appl. Math. Model. 32 (2008), 2347-2359.

[40] H. ZHAO, Global asymptotic stability of Hopfield neural networks involving distributed delays, Neural Networks 17 (2004), 47-53.

[41] J. ZhOU, S. Y. Li AND Z. G. YANG, Global exponential stability of Hopfield neural networks with distributed delays, Appl. Math. Model. 33 (2009), 1513-152. 
Journal of Mathematical Inequalities www.ele-math.com jmi@ele-math.com 